\title{
Composição Específica e Distribuição da Comunidade de MACRÓFITAS AQUÁticas NO RESERVATÓRIO DE AIMORÉS ${ }^{1}$
}

\author{
Aquatic Macrophytes Community and Colonization on Aimorés Reservoir \\ PITELLI, R.L.C.M. ${ }^{2}$, PITELLI-MERENDA, A.M.C.M. ${ }^{2}$, PITELLI, R.A. ${ }^{3}$, SIQUEIRA, R.C. ${ }^{4}$, \\ BARBOSA, H.O. ${ }^{4}$ e JESUS, L. ${ }^{4}$
}

\begin{abstract}
RESUMO - O reservatório de Aimorés é formado pelo represamento do Rio Doce e tem duas partes distintas: uma porção do rio que foi alagada e um canal de adução formado pelo desvio do rio em direção à usina geradora de energia elétrica. O levantamento das populações de macrófitas aquáticas presentes e o dimensionamento da área infestada são de suma importância para estabelecimento e avaliação do plano de manejo do reservatório e foi o objetivo deste trabalho. A colonização do reservatório cresceu de 39,2 para 92,5 hectares entre os meses de março e junho de 2009, decrescendo paulatinamente no período posterior, até atingir 39,9 hectares em janeiro de 2010. Esse decréscimo foi atribuído à implementação de plano de manejo, especialmente pela destruição de habitats para crescimento de Eichhornia crassipes. A comunidade de macrófitas aquáticas apresentou 31 espécies, pertencentes a 16 famílias botânicas. As espécies mais frequentes foram E. crassipes, Salvinia molesta, Paspalum repens, Oxycaryum cubense, Urochloa subquadripara e Hymenachne amplexicaulis. A família botânica mais representativa em termos de riqueza em espécies foi Poaceae, com seis representantes, seguida por Cyperaceae, com três.
\end{abstract}

Palavras-chave: Eichhornia crassipes, manejo de macrófitas, Oxyscaryum cubense, Salvinia molesta.

ABSTRACT - The Aimorés reservoir is formed by the construction of a dam across a river called Rio Doce It is divided into two different portions, one that was flooded, and another consisting of an adduction channel formed by the deviation of the river towards a power plant. It is of paramount importance to estimate the populations of aquatic macrophytes and determine which areas have been infested, in order to employ and assess a management plan for this reservoir, thus, this was the main objective of this work. Colonization rates have increased from 39.2 to 92.5 hectares from March to June in 2009, and have gradually decreased on the following season, reaching down to 39.9 hectares in January 2010. Such decrease was associated with the implementation of a management plan, especially due to the destruction of habitats that provide the growth of Eichhornia crassipes. In the macrophytes community, 31 species belonging to 16 botanical families were identified. The most commonly found species were E. crassipes, Salvinia molesta, Paspalum repens, Oxycaryum cubense, Urochloa subquadripara, and Hymenachne amplexicaulis. The most representative botanical family in terms of species richness was Poaceae with six representatives, followed by Cyperaceae with three representatives.

Keywords: Eichhornia crassipes, aquatic weed management, Oxyscaryum cubense, Salvinia molesta.

\section{INTRODUÇÃO}

A construção de reservatórios de água para abastecimento público, produção de energia elétrica, irrigação ou regularização de vazão é uma das mais importantes intervenções humanas nos sistemas hídricos continentais. Os reservatórios transformam corpos hídricos lóticos em sistemas lênticos e alteram expressivamente as condições químicas, físicas e

1 Recebido para publicação em 29.11.2013 e aprovado em 5.2.2014.

2 ECOSAFE - Agricultura e Meio Ambiente SS Ltda., Brasil <rlpitelli@ecosafe.agr.br>; ${ }^{3}$ Universidade Estadual Paulista, JaboticabalSP, Brasil; ${ }^{4}$ Usina de Aimorés - Hidrelétrica Eliezer Batista. 
bióticas em relação às condições originais. Quando o equilíbrio do ecossistema aquático é alterado, especialmente por intervenções antrópicas, podem ocorrer alterações nas importâncias relativas das populações nas diferentes comunidades presentes em todas as guildas tróficas. Na comunidade de macrófitas esse fenômeno é bastante evidente, com o desenvolvimento excessivo de algumas populações em detrimento de outras, formando colonizações pouco diversificadas, algumas praticamente monoespecíficas, acarretando prejuízos ao ambiente e ao uso múltiplo da água e do corpo hídrico.

A identificação das macrófitas aquáticas que ocorrem em um reservatório é de suma importância no estabelecimento de estratégias de manejo do corpo hídrico e identificação precoce de espécies que potencialmente poderiam causar danos aos usos múltiplos ou à qualidade da água do reservatório. Com o conhecimento das espécies que colonizam o reservatório, é possivel inferir os efeitos da presença de determinada espécie para o meio ambiente, as atividades operacionais e de geração do corpo hídrico e as técnicas de manejo para contenção de sua expansão populacional.

Vários levantamentos dessa natureza foram realizados e publicados. Martins et al. (2008) realizaram o levantamento das espécies de macrófitas aquáticas que infestavam 18 reservatórios do Estado de São Paulo e identificaram 39 espécies, inseridas em 21 famílias botânicas diferentes. As cinco mais frequentes nos reservatórios de Porto Primavera e Jupiá foram Salvinia auriculata, Eichhornia crassipes, Cyperus sp., Pistis stratiotes e Typha latifolia, encontradas em 97,$4 ; 79,5 ; 51,3 ; 46,2 ;$ e $46,2 \%$ dos reservatórios, respectivamente. As espécies do grupo das plantas submersas, Ceratophyllum demersum, Egeria najas e Egeria densa, apresentaram valores de frequência absoluta e relativa na ordem de 42,9 e $5,7 \%, 50,0$ e $6,7 \%$ e 60,0 e $8,0 \%$, respectivamente.

Pivari et al. (2007), realizando o levantamento florístico de cinco baceiros no Pantanal, no Mato Grosso do Sul, verificaram a presença de 66 espécies de macrófitas aquáticas, inseridas em 27 famílias botânicas. Apenas duas espécies, Ludwigia leptocarpa e
O. cubense, estiveram presentes nos cinco baceiros, enquanto as famílias comuns a todos esses foram Asteraceae, Cyperaceae, Onagraceae, Poaceae e Polygonaceae. Pivari et al. (2008) estudaram as macrófitas aquáticas na Lagoa Silvana, no Vale do Rio Doce, e constataram a presença de 56 espécies de macrófitas aquáticas, pertencentes a 46 gêneros e distribuídas em 35 famílias botânicas, sendo Cyperaceae e Onagraceae as mais representativas, com seis representantes cada. Esses são alguns resultados que mostram a grande variação entre o número de espécies e riqueza de espécies entre corpos hídricos, pois estas dependem de inúmeras características, como uniformidade de condições de profundidade, de características da água e outras.

Juntamente com a identificação das espécies, a quantificação da área infestada fornece, para quem maneja o reservatório, um grande volume de dados para estimativa de gastos e organização de logística de retirada e transporte da biomassa obtida nas atividades de retirada mecânica.

Assim, o objetivo deste trabalho foi avaliar a composição específica e a área de colonização das macrófitas aquáticas presentes no reservatório da UHE Eliezer Batista, do Consórcio da Hidrelétrica de Aimorés.

\section{MATERIAL E MÉTODOS}

O presente trabalho foi conduzido na Usina Hidrelétrica Eliezer Batista, que está localizada no médio Rio Doce, divisa dos Estados de Minas Gerais e Espírito Santo, ocupando as áreas dos municípios mineiros de Aimorés, Ituêta e Resplendor e Baixo Guandu, no Espírito Santo. Doravante esta usina será referida apenas como UHE Aimorés, e seu lago, como reservatório de Aimorés. Seu eixo está situado a montante do final do remanso do reservatório da Usina Hidrelétrica de Mascarenhas (cerca de $10 \mathrm{~km})$ e da foz do Rio Manhuaçu (3 km). O reservatório apresenta área total de $30,9 \mathrm{~km}^{2}$, profundidade média de $16 \mathrm{~m}$ e cota máxima de $92 \mathrm{~m}$. O reservatório de Aimorés possui duas partes distintas, com características diversas para o crescimento de macrófitas aquáticas: (i) canal de adução e (ii) a porção Rio Doce. São duas regiões com características 
de fluxo e morfometrias de fundo completamente diferentes. A porção Rio Doce tem pequena proporção de áreas com baixa profundidade, as quais são situadas bem próximas às margens. Na maior parte desse corpo hídrico o ambiente é semilótico, com elevada taxa de renovação de água.

O canal de adução é um lago artificial formado pelo desvio parcial do Rio Doce e tem grande proporção de ambientes lênticos e baixa taxa de renovação de água. Nesse canal de adução, em virtude da topografia da área alagada, há regiões rasas entremeadas com profundas, porém as áreas com pequena profundidade são extensas. Devido ao caráter lêntico e à grande quantidade de sedimentos transportados pela água do Rio Doce, há uma sedimentação inicial no canal de adução, que favorece o desenvolvimento de macrófitas aquáticas.

Foram realizadas campanhas de campo a cada 30 dias durante o período de março de 2009 e janeiro de 2010. Em cada levantamento, todo o reservatório foi percorrido de barco em sua região litorânea, braços e lagoas marginais. As espécies de macrófitas presentes foram identificadas por meio de comparação morfológica, consulta de literatura especializada e consulta a especialistas.

Como o reservatório apresenta uma colonização de macrófitas aquáticas caracterizada por uma faixa continua ao longo das margens e lagoas, que muitas vezes pode apresentar valores de largura de até 250 metros, a metodologia de avaliação da área ocupada foi realizada mediante caminhamento com barco nas bordas do início ao fim de cada segmento de infestações, marcando todos os segmentos. Cada segmento foi medido em sua extensão, utilizando o GPS, sendo sua largura avaliada mediante uso de medidor de distância Nikon ProStaff Laser 440. A largura da infestação foi considerada como a distância da margem interna do banco de macrófitas até a margem do reservatório, considerando que praticamente todas as colonizações marginais estabelecidas começam nas margens e se projetam na lâmina d'água. Essa distância não é uniforme dentro de uma mesma infestação. Portanto, para cálculo da área foi utilizado o valor da média de largura, baseado em três a quatro medições por segmento, conforme o local, a uniformidade e o tamanho da colonização. No caso de infestações que apresentavam contornos mais ou menos regulares (forma de quadrado, retângulo ou triângulo), foram realizadas medidas de seus lados, e sua área foi estimada por cálculos geométricos tradicionais. Dos bancos de macrófitas que estavam sendo carregadas pela correnteza, apenas foram medidos aqueles que formavam complexos sólidos, como ilhas flutuantes.

O cálculo da área de infestação em cada segmento foi realizado mediante utilização do software GPS Trackmaker ${ }^{\circledR}$ Profissional, versão 4.6, e as áreas, somadas para determinação do nivel de infestação total e de cada segmento do reservatório de Aimorés.

\section{RESULTADOS E DISCUSSÃO}

No reservatório de Aimorés foram identificadas 31 espécies de macrófitas aquáticas, pertencentes a 16 famílias botânicas (Tabela 1). Considerando que é um reservatório jovem, a riqueza de espécies pode ser considerada alta, mas há um longo histórico de colonização do Rio Doce e de seus afluentes com elevada atividade antrópica, incluindo introdução de macrófitas exóticas (Pivari et al., 2008).

Entre as espécies encontradas no reservatório de Aimorés, E. crassipes (aguapé) pode ser considerada a mais importante, devido à sua intensa proliferação e a problemas causados na geração de energia elétrica e na composição do preço por unidade de energia gerada. A maior importância dessa macrófita pode ser verificada na porção Rio Doce, onde desenvolve grandes populações nas regiões de paliteiros (restos mortos de árvores inundadas). Uma grande contribuição ao crescimento dessa macrófita na porção Rio Doce é o lançamento de efluentes de um laticínio, onde há vigorosa e exclusiva colonização de aguapé.

Quando flutuando em áreas profundas, o crescimento é muito lento e as plantas são bastante danificadas por inimigos naturais. No entanto, grandes bancos de E. crassipes se formam em áreas pouco profundas, onde as plantas podem fixar suas raízes no sedimento e extrair nutrientes. Estas áreas pouco profundas apresentaram grande quantidade de restos de plantas de ubá (Gynerium sagittatun) 
Tabela 1 - Populações de macrófitas aquáticas identificadas no reservatório de Aimorés no período de março de 2009 a janeiro de 2010

\begin{tabular}{|l|l|}
\hline \multicolumn{1}{|c|}{ Família } & \multicolumn{1}{|c|}{ Espécie } \\
\hline Alismataceae & Sagittaria montevidensis CHAM. \& SCHLECHT \\
\hline Amaranthaceae & Alternanthera philoxeroides (MART.) GRISEB. \\
\hline Araceae & Pistia stratiotes L \\
\hline Azollaceae & Azolla filiculoides LAM \\
\hline Commelinaceae & Commelina diffusa BURM. \\
\hline Cyperaceae & Oxycaryum cubense (POEPP. \& KUNTH) K.LYE \\
\hline Cyperaceae & Eleocharis elegans (H.B.K.) ROEM. \& SCHULT \\
\hline Cyperaceae & Cyperus ferax L.C.RICH. \\
\hline Fabaceae & Sesbania exasperata H.B.K. \\
\hline Fabaceae & Neptunia plena (L.) BENTH. \\
\hline Haloragaceae & Myriophyllum aquaticum (VELL.) VERDC \\
\hline Hydrocharitaceae & Egeria dens PLANCH. \\
\hline Nymphaeaceae & Nymphaea ampla (SALISB.) DC. \\
\hline Onagraceae & Ludwigia elegans (CAMB.) HARA \\
\hline Poaceae & Hymenachne amplexicaulis (RUDGE) NEES \\
\hline Poaceae & Paspalum repens BERG. \\
\hline Poaceae & Urochloa subquadripara (TRIN./LINK) HITCHC \\
\hline Poaceae & Echinochloa polystachya (H.B.K.) HITCHC. \\
\hline Poaceae & Panicum repens L. \\
\hline Poaceae & Panicum rivulare TRIN. \\
\hline Polygonaceae & Polygonum lapathifolium L \\
\hline Polygonaceae & Polygonum hydropiperoides L \\
\hline Pontederiaceae & Eichhornia crassipes (MART.) SOLMS \\
\hline Pontederiaceae & Eichhornia azurea (SW.) KUNTH \\
\hline Salviniaceae & Salvinia molesta MITCH. \\
\hline Salviniaceae & Salvinia herzogii DE LA SOTA \\
\hline Typhaceae & Typha dominguensis (L.) PERS./KUNTH \\
\hline
\end{tabular}

mortas pelo alagamento, as quais formavam densos paliteiros, o que dá estabilidade e suporte ao crescimento desta macrófita aquática, justamente em águas, rasas onde as raízes dela podiam atingir o sedimento e absorver nutrientes para suportar seu profuso crescimento. O aguapé originário da Região Amazônica é a principal invasora de corpos hídricos, em termos mundiais. É uma planta flutuante, carnosa, acaule, apresentando talos simpodiais carnosos e cilíndricos, que promovem a reprodução assexuada. As folhas visualizadas nas plantas são, na verdade, filódios, lisos e glabros, que se arranjam em roseta a partir da base da planta. Os pecíolos mostram uma base bastante inflada com presença de tecido aerenquimatoso. O aguapé pode enraizar no substrato se a profundidade for baixa (Kissmann \& Groth, 1997).

Outro táxon de grande importância no reservatório de Aimorés é o complexo Salvinia (S. molesta e S. herzogii), que infesta grande área do reservatório, principalmente no canal de adução. As salvínias se desenvolvem nas áreas marginais bastante lênticas das lagoas do canal de adução, formando grandes bancos, que são base de sustentação para o crescimento epifitico de outras populações, como Paspalum repens, Urochloa subquadripara, Oxyscayium cubense e Hymenachne amplexicaulis. As 
plantas do gênero Salvinia são macrófitas aquáticas flutuantes. Estas plantas, originárias da América do Sul, sob condições favoráveis, formam grande massa vegetativa sobre a superficie da água. A salvinia é uma planta inferior (pteridófita), acaule, rizomatosa. Das gemas do rizoma se formam folhas modificadas, em número de três: duas ficam expostas na superficie (frondes) e uma permanece submersa, substituindo as raízes, que não existem. Sua reprodução ocorre preferencialmente por via assexuada, mas também ocorre a formação de esporângios e esporos na folha submersa (Kissmann \& Groth, 1997).

A macrófita $O$. cubense é bastante abundante nas áreas lênticas do canal de adução e inicia sua colonização mais rapidamente sobre bancos do complexo Salvinia e, com menor frequência, sobre bancos de $P$. stratiotes e E. crassipes. Oxycaryum cubense é uma representante da família Cypercaeae de hábito epífito, que se desenvolve sobre populações de macrófitas flutuantes. Essa associação foi primeiramente descrita por Tur (1965), que observou o estabelecimento do O. cubense sobre Salvinia minima no Rio Paraná.

As populações de Typha dominguensis e Eichhornia azurea colonizaram as áreas rasas da porção Rio Doce. Essas macrófitas, por suas características de crescimento, não interferem na geração de energia elétrica e não formaram grandes populações nas áreas rasas do canal de adução. A população de $U$. subquadripara aumentou expressivamente no período de avaliações, principalmente no canal de adução, onde apresenta crescimento epifítico sobre aguapé e salvínia, especialmente na porção mais rasa das lagoas. Essa gramínea exótica tem perspectiva de se tornar uma macrófita bastante problemática no reservatório de Aimorés, em razão do histórico que apresenta em outros reservatórios. Como sua infestação é mais recente, poucos incidentes envolvendo essa planta ocorreram na tomada d'água da casa de força da UHE Aimorés.

U. subquadripara é uma graminea estolonífera, de hábito subereto a prostrado, com colmos carnosos e glabros, muito ramificantes, formados a partir de estolões. A planta apresenta folhas com lâminas planas, lanceoladas, de base larga, com ápice acuminado. Quando ingerida por vários dias, pode causar intoxicações severas no gado (Kissmann \& Groth, 1997). Nos corpos hídricos das regiões Sudeste e Centro-Oeste do Brasil, já se destaca como uma das principais populações de comunidades de macrófitas aquáticas, como foi observado por Velini et al. (2005), em Barra Bonita (SP), e Pitelli et al. (2008), no reservatório de Santana em Piraí (RJ), e comentado por Agostinho et al. (2005), nos reservatórios da bacia do Rio Paraná.

A população de $P$. stratiotes no reservatório de Aimorés apenas foi observada em pequenas colonizações, mas as plantas estavam bastante prejudicadas por insetos, especialmente o lepidóptero do gênero Samea multiplicalis. Provavelmente, essa é a principal causa de essa macrófita não ter se tornado problema nesse reservatório. Pistia stratiotes (alfaced'água) é uma macrófita aquática flutuante, acaule, estolonifera, com folhas esponjosas dispostas de forma espiralada, em roseta compacta. As folhas são esponjosas, com presença de tecido aerenquimatoso, acanaladas longitudinalmente e com coloração verde-azulada. Sua inflorescência, típica das aráceas, é formada por flores aclamídeas e unissexuais, muito pequenas, sobre um espádice protegido por uma espata branca (Kissmann \& Groth, 1997). Outra planta com bastante expressão nesse reservatório é $P$. repens. A germinação das sementes ocorre nas margens úmidas, e as plantas crescem se projetando sobre a lâmina d’água, pois têm estruturas de flutuação. Nas margens do canal escavado, que apresenta regime mais lótico, apresenta crescimento epifitico e se fixa em pequenas colonizações marginais de salvínia e de aguapé, o que evolui para a formação de assembleias relativamente grandes dessas plantas, que, nessas condições, são arrancadas pelo fluxo e transportadas a jusante.

A população de Polygonum lapathifolium está confinada às áreas pouco profundas e, em várias ocasiões, sucede as colonizações de plantas flutuantes, especialmente aguapé. Com suas raízes fixadas no sedimento, exercem forte competição e acabam por eliminar as populações de plantas flutuantes. Os bancos dessa macrófita tornam-se perenes e propiciam condições para o estabelecimento de 
plantas arbóreas pioneiras típicas de áreas alagadas. O controle mecânico frequente exercido pela usina de Aimorés impede que esse processo se desenvolva. De acordo com Kissmann \& Groth (2000), a erva-de-bicho, como popularmente chamada, é uma planta herbácea, de caule cilíndrico, suculento, simples ou pouco ramificado, com núcleo esponjoso e entrenós relativamente curtos. As folhas são alternas, pecioladas, ocorrendo uma por nó. As folhas mais velhas apresentam minúsculas glândulas, que secretam uma substância pegajosa. A planta apresenta inflorescência terminal, com rácemos especiformes longamente pedunculados. Essa planta poderá ser utilizada em futuro plano de manejo de macrófitas, no controle de habitats adequados ao crescimento do aguapé.

Egeria densa é uma macrófita submersa que começou a ocorrer nas áreas lênticas do canal de adução, porém é uma planta bastante problemática no reservatório de Jupiá (Velini, 2005; Mustafá et al., 2010). Devido à baixa profundidade média do canal e por apresentar substrato rochoso, acredita-se que essa colonização ficará restrita às áreas finais das lagoas do canal de adução e dificilmente terá biomassa suficiente para interferir na geração. Segundo Kissmann \& Groth (1997), a espécie Egeria densa é originária da América do Sul. É uma planta aquática de hábito submerso, perene, que se desenvolve em ampla faixa de $\mathrm{pH}$ da água. Planta tenra, densamente enfolhada, com as folhas dispostas regularmente à volta de um caule cilíndrico e pouco ramificado (aspecto cilindrico). As folhas são lineares, tenras, de ápice agudo e margens finamente serrilhadas. Flores formadas a partir de espata que saem das axilas das folhas, com três pétalas brancas, dispostas logo acima da lâmina d'água.

As espécies Hynmenachne amplexicaulis e Panicum rivulare são duas gramíneas competitivas, mas suas populações são pequenas, dispersas e restritas às áreas marginais. No caso de $H$. amplexicaulis, observou-se que ela projeta seu crescimento sobre a lâmina d'água e sobre bancos de plantas flutuantes, o que pode, no futuro, causar problemas. Alternanthera philoxeroides ocorre em pequenas colonizações, assim como $M$. aquaticum, S. exasperata, C. ferax, S. montevidensis e
Ludwigia elegans, que apresentam colonização restrita a áreas rasas e marginais.

Carvalho et al. (2003), em levantamento florístico do reservatório de Barra Bonita, encontraram 17 espécies de macrófitas aquáticas, que ocupavam uma área de 1,87 hectare, sendo Brachiaria mutica, U. subquadripara e E. crassipes as macrófitas com maiores infestações. Levantamentos conduzidos por Bini et al. (2005) no reservatório Cachoeira Dourada (GO-MG) identificaram 16 táxons de macrófitas aquáticas, distribuídos em 12 famílias botânicas. Estes autores constataram que as espécies de E. azurea e E. crassipes foram as populações mais frequentes, com valores de 44 e $92 \%$, respectivamente. Cervi et al. (2009) avaliaram a comunidade de macrófitas aquáticas na região do município de General Carneiro (PR) e identificaram 117 espécies de macrófitas aquáticas, distribuídas em 45 famílias botânicas - um resultado considerado com alta diversidade se comparada com a dos reservatórios de usinas hidrelétricas. A família Cyperaceae representou $22 \%$ dos táxons identificados, com um total de 22 táxons, seguida pelas famílias Poaceae, $\operatorname{com} 8$, Asteraceae, com 7, e Polygonaceae, com 6. Estes autores também verificaram que a maior parte das espécies apresentava hábito emergente (57 espécies). Essa tendência também foi observada no presente trabalho, onde 17 espécies apresentaram hábito emergente ou marginal, representando $54,8 \%$ da comunidade.

Na Tabela 2 é apresentada a área da lâmina d'água do reservatório de Aimorés colonizada pela comunidade de macrófitas aquáticas nos seus diferentes segmentos.

Houve forte variação na área total de superfície de lâmina d'água colonizada, variando de 39,2 hectares em março de 2009 a 92,5 hectares em julho, e novamente caindo para 39,9 hectares em janeiro de 2010. A porção Rio Doce, apesar de se apresentar com uma área de superficie de água maior que a do canal de adução, mostrou infestação menor da comunidade de macrófitas aquáticas, com exceção do levantamento de setembro de 2009. A grande redução na área infestada pelas macrófitas aquáticas no mês de setembro ocorreu 
Tabela 2 - Áreas de lâmina d’água do reservatório de Aimorés colonizada por macrófitas aquáticas durante o ano de 2009

\begin{tabular}{|c|c|c|c|c|c|c|c|}
\hline \multirow{3}{*}{ Mês } & \multicolumn{3}{|c|}{ Lagoa } & \multirow{2}{*}{$\begin{array}{c}\text { Margens do } \\
\text { canal }\end{array}$} & \multirow{2}{*}{$\begin{array}{c}\text { Canal de } \\
\text { Adução }\end{array}$} & \multirow{2}{*}{$\begin{array}{l}\text { Porção Rio } \\
\text { Doce }\end{array}$} & \multirow{2}{*}{ Tota } \\
\hline & Cueca & Vala Seca & Elcio & & & & \\
\hline & \multicolumn{7}{|c|}{ (ha) } \\
\hline Março & 2,9 & 24,4 & 0,6 & 1,4 & 28,0 & 11,3 & 39,2 \\
\hline Abril & 18,4 & 29,7 & 2,0 & 3,2 & 50,2 & 33,4 & 83,6 \\
\hline Maio & 18,4 & 27,8 & 4,0 & 1,5 & 50,2 & 30,4 & 80,6 \\
\hline Junho & 18,4 & 35,2 & 7,4 & 4,4 & 61,1 & 31,4 & 92,5 \\
\hline Julho & 18,4 & 32,1 & 7,0 & 3,2 & 57,6 & 34,5 & 92,1 \\
\hline Agosto & 5,4 & 29,2 & 7,1 & 0,6 & 41,7 & 37,7 & 79,4 \\
\hline Setembro & 6,7 & 17,8 & 8,4 & 1,0 & 32,9 & 34,2 & 67,1 \\
\hline Outubro & 8,7 & 18,8 & 12,6 & 2,0 & 40,2 & 26,8 & 67,0 \\
\hline Novembro & 7,8 & 17,9 & 10,1 & 2,9 & 35,8 & 19,2 & 55,0 \\
\hline Dezembro & 5,4 & 18,1 & 7,9 & 2,2 & 31,4 & 16,2 & 47,6 \\
\hline Janeiro & 4,3 & 15,3 & 8,4 & 2,7 & 28,1 & 11,8 & 39,9 \\
\hline
\end{tabular}

principalmente pela colheita mecânica, realizada pela usina, na lagoa da Vala Seca. Essa retirada das macrófitas é feita por meio de máquinas flutuantes, que deslocam essas populações das áreas marginais e as lançam para o leito do canal. Essa biomassa é carregada pela correnteza e se prende à barreira flutuante instalada antes da tomada d'água, onde uma colhedeira retira a biomassa deslocada. Esse processo é realizado constantemente ao longo do ano pela usina, evitando que as macrófitas aquáticas atinjam populações muito grandes. A lagoa da Cueca também sofreu redução em suas infestações no mês de agosto, devido à intervenção do controle mecânico. A importância da retirada dos paliteiros será comentada adiante.

A mesma tendência de variação da área ocupada pela comunidade de macrófitas aquáticas pode ser observada na porção Rio Doce, que teve seu maior pico de infestação entre os meses de julho e setembro. No entanto, as populações presentes na porção Rio Doce foram diferentes das encontradas no canal de adução. Pela própria característica do Rio Doce, com águas mais profundas e maior velocidade de fluxo de água, as infestações se localizavam em remansos formados pela inundação de áreas adjacentes e de pequenos córregos. Foi nessa porção do reservatório em que foram encontradas populações de Ludwigia elegans, Sesbania exasperata,
Polygonum lapathifolium e Polygonum hidropiperoides.

Uma característica interessante da porção Rio Doce foi a presença de grandes áreas com paliteiros de ubá, principalmente nas áreas mais a montante, próximas das cidades de Itueta e Resplendor, MG. Esses paliteiros servem como local de "ancoragem" de macrófitas aquáticas flutuantes, sobretudo de aguapé. Nesses locais foram formados grandes bancos dessa macrófita aquática, que aos poucos se soltavam e chegavam ao canal de adução. Na porção Rio Doce do reservatório ficou bastante evidente a importância da retirada dos paliteiros de Ubá nas margens do reservatório e de ilhas, refletindo nas quedas dos tamanhos das áreas colonizadas a partir de setembro de 2009. Essa foi a primeira ação de manejo preventivo de macrófitas aquáticas inserida neste reservatório.

No caso do reservatório de Aimorés, as lagoas do canal de adução apresentam áreas muito rasas, que normalmente estão infestadas de macrófitas aquáticas adaptadas ao ambiente de várzea. Também apresentam estreitamento de algumas extremidades, o que, quando completamente infestadas por macrófitas flutuantes ou enraizadas, dificulta o acesso e visualização em áreas mais distantes, provocando erros de amostragem com o distanciômetro. Outras técnicas podem ser utilizadas, as quais reduzem drasticamente 
esses erros de amostragem, apesar de apresentarem custos bem mais elevados. Um exemplo é o trabalho de Carvalho et al. (2003), que utilizaram notas de amostragem e imagens de satélite para estimar a área ocupada por macrófitas aquáticas no reservatório de Barra Bonita, SP. No entanto, apesar de fornecerem dados mais confiáveis, são técnicas de custo mais elevado e não dispensam a identificação dos táxons no campo.

Em conclusão, o reservatório de Aimóres, apesar de recente, apresenta boa riqueza de espécies, destacando-se o aguapé e as salvinias. Um comportamento bastante observado neste reservatório é o crescimento epifitico de $O$. cubense, $U$. subquadripara e $P$. repens sobre colonizações de macrófitas flutuantes, o que pode dificultar a colheita mecânica. A intervenção nos habitats de crescimento de aguapé mostrou ser uma técnica eficiente de controle preventivo.

\section{LITERATURA CITADA}

AGOStinho, A. A.; THOMAZ, S. M.; GOMES, L. C. Conservação da biodiversidade em águas continentais do Brasil. Megadiversidade, v. 1, n.1, p. 70-78, 2005.

BINI, L. O. M. et al. Patterns of the aquatic macrophyte cover in Cachoeira Dourada reservoir (Go-Mg). Braz. J. Biol., v. 65, n. 1, p. 19-24, 2005.

CARVALHO, F. T. et al. Plantas aquáticas e nível de infestação das espécies presentes no reservatório de Barra Bonita, no Rio Tietê. Planta Daninha, v. 21, p. 5-19, 2003. (Número Especial)

CERVI, A. C. et al. Macrófitas aquáticas do município de General Carneiro, Paraná, Brasil. Biota Neotrop., v. 9, n. 3, p. 215-222, 2009.
KISSMANN, K. G.; GROTH, D. Plantas infestantes e nocivas. 2.ed. São Paulo: BASF, 1997. Tomo I. 825 p.

KISSMANN, K. G.; GROTH, D. Plantas infestantes e nocivas. 2.ed. São Paulo: BASF, 2000a. Tomo II. 825 p.

KISSMANN, K. G.; GROTH, D. Plantas infestantes e nocivas. 2.ed. São Paulo: BASF, 2000b. Tomo III. 722 p.

MARTINS, D. et al. Caracterização da comunidade de plantas aquáticas de dezoito reservatórios pertencentes a cinco bacias hidrográficas do estado de São Paulo.

Planta Daninha, v. 26, n. 1, p. 17-32, 2008.

MUSTAFA, A. L. et al. A experiência da CESP no manejo e controle de macrófitas no reservatório da UHE Souza Dias (Jupiá). Ação Amb., v. 13, n. 43, p. 17-26, 2010.

PITELLI, R. L. C. M. et al. Dinâmica da comunidade de macrófitas aquáticas no reservatório de Santana, RJ. Planta Daninha, v. 26, n. 3, p. 473-480, 2008.

PIVARI, M. O.; POTT, V. J.; POTT, A. Macrófitas aquáticas de ilhas flutuantes (baceiros) nas sub-regiões do Abobral e Miranda, Pantanal, MS, Brasil. Acta Bot. Bras. v. 22, n. 2, p. 563-571, 2008a.

PIVARI, M. O. D. et al. Macrófitas aquáticas da Lagoa Silvana, Vale do Rio Doce, Minas Gerais, Brasil. Iheringia, Sér. Bot., v. 63, n. 2, p. 321-327, 2008b.

VELINI, E. D. Desenvolvimento de técnicas e equipamentos para o monitoramento e controle de plantas aquáticas. 2005. 238 f. Tese (Livre Docência) Faculdade de Ciências Agronômicas, Universidade Estadual Paulista, Botucatu, 2005.

VELINI, E. D. et al. Caracterização da qualidade de água e sedimento na UHE Americana relacionados à ocorrência de plantas aquáticas Planta Daninha, v. 23, n. 2, p. 215-223, 2005.

TUR, N. M. Un caso de epifitismo acuático. B. Soc. Argentina Bot., v. 10, n.1, p. 323-327, 1965. 